\title{
Avaliação da Atividade Citotóxica das Folhas de Bauhinia Rufa (Bong.) Steud. (Fabaceae) Contra Linhagens de Células Tumorais
}

\author{
Weber M. S. Junior, Lauanyy E. S. Arini, Danielly F. dos Santos, \\ Antônio C. S. Menezes, Mirley L. dos Santos, Manoel O. de \\ Moraes, Cláudia do Ó Pessoa \& Andréa F. Moura
}

Os produtos naturais são potenciais fontes de moléculas antitumorais. Assim, este trabalho objetivou avaliar a citotoxicidade in vitro dos extratos das folhas de Bauhinia rufa (Bong.) Steud. contra as linhagens de células HL-60, PC-3 e HCT-116. Os extratos foram obtidos por maceração a frio com hexano (BRFH), diclorometano (BRFD), acetato de etila (BRFA) e metanol (BRFM). Foram submetidos à triagem por meio da redução do MTT. BRFAC e BRFM apresentaram-se tóxicos frente à HL-60 com inibição o crescimento de 94,5 e $83,46 \%$, respectivamente. Portanto, tem-se como perspectiva o isolamento dos constituintes químicos bioativos destes extratos.

Palavras-chave: Viabilidade Celular; Fitoquímica; Antitumoral.

Natural products are potential sources of antitumor molecules. Thus, this work aimed to evaluate the in vitro cytotoxicity of Bauhinia rufa (Bong.) Steud. leaf extracts against the HL-60, PC-3 and HCT-116 cell lines. The extracts were obtained by cold maceration with hexane (BRFH), dichloromethane (BRFD), ethyl acetate (BRFA) and methanol (BRFM). They were submitted to screening by means of MTT reduction. BRFAC and BRFM were toxic to HL-60 with growth inhibition of 94.5 and $83.46 \%$, respectively. Therefore, the isolation of the bioactive chemical constituents of these extracts is a perspective.

Keywords: Cell viability; Phytochemistry; Antitumor. 


\section{Introdução}

Os produtos naturais são potenciais fontes de moléculas farmacologicamente úteis para o tratamento de diversas doenças, inclusive para o tratamento do câncer. Dentre os 246 agentes anticancerígenos utilizados nos últimos 75 anos, cerca de $72 \%$ são moléculas com origem em produtos naturais ${ }^{1,2}$.

Até a década de 1950, as plantas não eram visadas como fonte de medicamentos pela indústria farmacêutica, no entanto, o interesse nas pesquisas aumentou significativamente após a inserção de novos métodos de rastreio de compostos biologicamente ativos em extratos ${ }^{3}$. Das mais de 350 mil espécies de plantas conhecidas, cerca de 1000 apresentam propriedades antitumorais significantes ${ }^{4,5,6}$.

Tratando-se de investigação farmacológica experimental, a avaliação da viabilidade celular e citotoxicidade de compostos ou extratos é realizada, várias vezes, pela medição da atividade mitocondrial através da redução de MTT (brometo de 3-(4,5-dimetiltiazol-2-il)-2,5difeniltetrazólio) ${ }^{7}$. Neste sentido, tem-se como exemplo o estudo da citotoxicidade dos isolados de Bauhinia kockiana Korth. (Fabaceae) contra as linhagens celulares MCF-7, PC-3, LNCaP, DU145 e HCT-116 $6^{8}$.

Nesse sentido, o presente trabalho objetivou avaliar a citotoxicidade in vitro dos extratos das folhas de Bauhinia rufa (Bong.) Steud. (Fabaceae) contra as linhagens de células tumorais HL-60, PC-3 e HCT-116.

\section{Material e Métodos}

\section{MATERIAL VEGETAL}

As folhas de B. rufa foram coletadas na cidade de Leopoldo de Bulhões - GO, em março de 2016. Foi identificada pela Profa. Dra. Mirley Luciene dos Santos. A exsicata depositada no Herbário da Universidade Estadual de Goiás (HUEG) sob o número de tombo 11.061.

\section{OBTENÇÃO DOS EXTRATOS}

As folhas de B. rufa foram pré-selecionadas, lavadas, secas em estufa sob circulação de ar, modelo MARCONI MA-035, a uma temperatura de 45 oC durante 48 horas, pulverizadas em moinho de facas, modelo MA-580, e armazenadas em erlenmeyers de dois litros. O material foi, então, submetido a maceração a frio, sucessivamente, com os solventes hexano, diclorometano, acetato de etila e metanol em ordem crescente de polaridade. O solvente orgânico foi roteoevaporado (TECNAL-120), em temperaturas abaixo de 40oC. Foram obtidos os extratos Hexânico (BRFH), Diclorometânico (BRFD), Acetato etílico (BRFA) e Metanólico (BRFM). O processo é ilustrado na Figura 1.

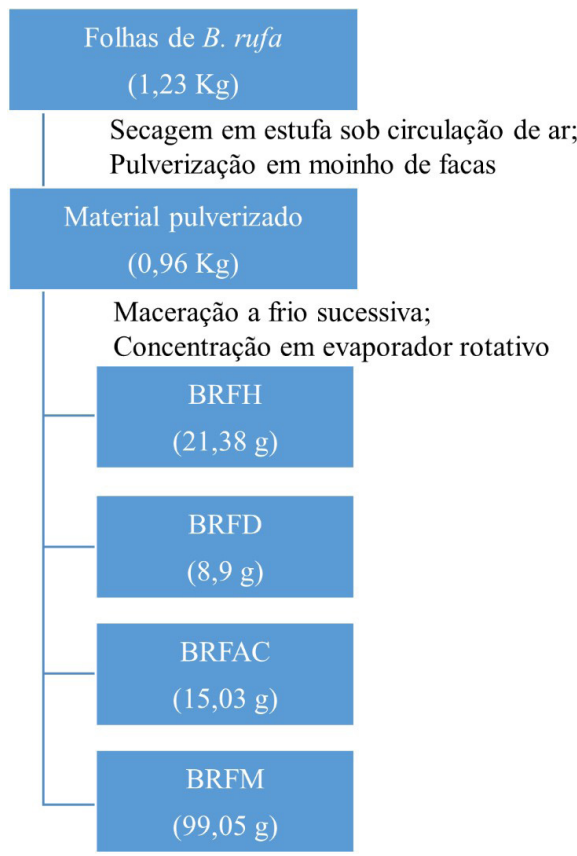

Figura 1. Obtenção e fracionamento dos extratos das Folhas de B. rufa.

\section{ENSAIO DE CITOTOXICIDADE IN VITRO PELO MTT}

Os extratos das folhas de B. rufa foram submetidos à triagem quanto citotoxicidade em células tumorais. Ensaios realizados no Laboratório de Oncologia Experimental da Universidade Federal do Ceará (UFC) por meio da redução do MTT $^{9}$. 
As linhagens de células utilizadas, HL-60 (leucemia), PC-3 (próstata) e HCT-116 (cólon) foram cedidas pelo Instituto Nacional do Câncer (US-NCI). Foram cultivadas em meio RPMI 1640, suplementado com $10 \%$ de soro fetal bovino e $1 \%$ de antibióticos, mantidas em incubadora a 37 ${ }^{\circ} \mathrm{C}$ e atmosfera contendo $5 \%$ de $\mathrm{CO}_{2}$.

Os extratos BRFH, BRFAC, BRFD, BRFM, foram diluídos em DMSO puro estéril e testados na concentração única de $50 \mu \mathrm{g} \cdot \mathrm{mL}^{-1}$, concentração adotada pelo laboratório como padrão para triagem.

As células foram plaqueadas na concentração de $3 \times 10^{5}$ cél. $\mathrm{mL}^{-1}$ para a linhagen HL-60, 1 x $10^{5}$ cél. $\mathrm{mL}^{-1}$ para PC-3 e 7 x $10^{4}$ cél.mL $\mathrm{mL}^{-1}$ para HCT-116. Após 24 horas de incubação, as células foram tratadas com os compostos-teste e incubadas por 72 horas em estufa a $5 \%$ de $\mathrm{CO}_{2}$ a $37^{\circ} \mathrm{C}$.

Ao término deste, as mesmas foram centrifugadas e o sobrenadante removido. Em seguida, foram adicionados $150 \mu \mathrm{L}$ da solução de MTT (sal de tetrazolium) a $1 \%$, e as placas foram incubadas por 3h. A absorbância foi lida, após dissolução do precipitado em $150 \mu \mathrm{L}$ de DMSO puro, em espectrofotômetro de placa a $595 \mathrm{~nm}$.

Os experimentos foram analisados segundo a média \pm desvio padrão da média (DPM) da porcentagem de inibição do crescimento celular, usando o programa GraphPad Prism.

\section{Resultados e Discussão}

\section{RENDIMENTO DOS EXTRATOS}

Partiu-se de 1,23 Kg de material fresco, que resultou em $0,96 \mathrm{Kg}$ de material seco e pulverizado. Após a extração, perfez-se massa final de 21,38 $\mathrm{g}$ de BRFH, 8,9 g de BRFD, 15,03 g de BRFAC e 99,05 g de BRFM.

\section{CITOTOXICIDADE IN VITRO PELO MTT}

O padão adotado pelo laboratório considera citotóxico o extrato capaz de inibir acima de $75 \%$ da proliferação celular. O Gráfico 1 mostra o percentual de Inibição do Crescimento celular (IC) apresentado após $72 \mathrm{~h}$ de tratamento com os extratos de B. rufa.

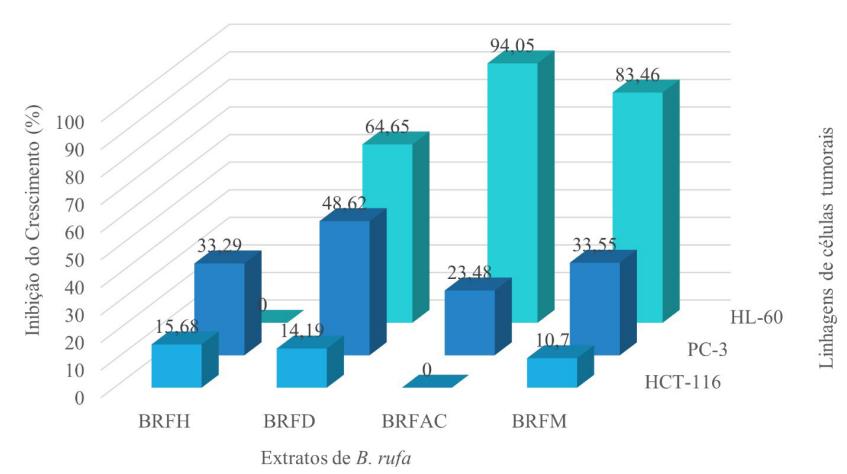

Gráfico 1. Percentual de Inibição do Crescimento tumoral (IC) in vitro dos extratos de $B$. rufa na concentração única de $50 \mu \mathrm{g} \cdot \mathrm{mL}-1$ frente às linhagens de células tumorais, determinado pelo método MTT após $72 \mathrm{~h}$ de tratamento"

Verifica-se que os extratos BRFAC e BRFM apresentaram efeito citotóxico apenas frente à linhagem HL-60 com inibição o crescimento de 94,5 e 83,46\%, respectivamente. Este resultado é observado com desvio padrão de $0,46 \%$ para BRFAC e $8,26 \%$ para BRFM. Os extratos apresentam-se pouco tóxicos frente à linhagem HCT-116.

\section{Conclusão}

Os resultados indicaram a citotoxicidade dos extratos acetato-etílico (BRFAC) e metanólico (BRFM) das folhas de B. rufa. Portanto, tem-se como perspectiva o isolamento dos constituintes químicos bioativos presentes nos extratos polares das folhas de B. rufa.

\section{Agradecimentos}

Os autores agradecem à Fundação Coordenação de Aperfeiçoamento de Pessoal de Nível Superior (CAPES) pelo suporte financeiro.

\section{Referências}

1. Newman, D. J.; Cragg, G. M. J. Nat. Prod. 2016, 79, 629.

2. Nogueira, R. C.; Cerqueira, H. F.; Soares, M. B. P. Expert Opin. 


\section{Artigo Geral 4}

Ther. Pat. 2010, 20, 145.

3. Phillipson, J. D. Phytochemistry. 2007, 68, 2960.

4. Ferraz, A.; Faria, D. H.; Benneti, M. N.; Rocha, A. B.;

Schwartsmann, G.; Henriques, A.; von Poser, G. L. Phytomedicine. 2005, $12,112$.

5. Mounce, R.; Smith, P.; Brockington, S. Nat. Plants. 2017, 3, 795.

6. Mukherjee, A. K.; Basu, S.; Sarkar, N.; Ghosh, A. C. Curr Med Chem. 2001, 8, 1467.

7. Boncler, M.; Różalski, M.; Krajewska, U.; Podsędek, A.; Watala, C. Journal of J. Pharmacol. Toxicol. Methods. 2014, 69,9.

8. Chew, Y. L.; Lim, Y. Y.; Stanslas, J.; Ee, G. C. L.; Goh, J. K. African J. Tradit. Complement. Altern. Med. 2014, 11, 291.

9. Mosmann, T. J. Immunol. Methods. 1983, 65, 55.

\section{Weber M. S. Junior', Lauanyy \\ E. S. Arini ${ }^{1}$, Danielly F. dos Santos ${ }^{1}$, Antônio C. S. Menezes ${ }^{1 *}$, Mirley L. dos Santos' ${ }^{1}$, Manoel $O$. de Moraes², Cláudia do Ó Pessoa $^{2} \&$ Andréa F. Moura ${ }^{2}$}

${ }^{1}$ Universidade Estadual de Goiás - Campus Anápolis de Ciências Exatas e Tecnológicas Henrique Santillo. Anápolis, GO.

${ }^{2}$ Universidade Federal do Ceará - Laboratório de Oncologia Experimental. Fortaleza, CE.

*E-mail: antonio.menezes@ueg.br 